\title{
Improved Cognitive Function and Emotional Condition Measured Using Electroencephalography in the Elderly during Horticultural Activities
}

\author{
Seon-Ok Kim \\ Department of Bio and Healing Convergence, Graduate School, Konkuk \\ University, Seoul 05029, South Korea
}

\author{
Su-Been Pyun \\ Department of Horticultural Therapy, Graduate School of Agriculture \\ and Animal Science, Konkuk University, Seoul 05029, South Korea
}

\begin{abstract}
Sin-Ae Park
Department of Bio and Healing Convergence, Graduate School, Konkuk University, Seoul 05029, South Korea; Department of Systems Biotechnology, Konkuk Institute of Technology, Konkuk University, Seoul 05029, South Korea

Additional index words. brain wave, gardening, horticultural therapy, profile of mood states

Abstract. The aim of this study was to compare the physiological and psychological effects in the elderly during horticultural and nonhorticultural activities as leisure activities. A total of 58 participants aged 65 or older (29 men and 29 women; average age, 74.0 \pm 4.7) whose cognitive function was within the normal range were included in this study. Participants performed four horticultural and four nonhorticultural activities for 2 min, respectively. The study had a cross-over experimental design. Electroencephalography was performed during all the activities. Subjective evaluation of emotions was performed using the Profile of Mood States immediately after each activity. The collected statistical data were analyzed using Duncan's test as a post-analysis of variance test to verify the differences in the results of electroencephalography and the Profile of Mood States according to the different activities. In the results of the electroencephalography, the relative beta, gamma, low-beta, and ratio of sensorimotor rhythm to theta indices indicate that the degree of brain activity in the prefrontal lobe was high during activities such as washing leaves, transplanting plants, and reading news. The results of the Profile of Mood States showed that during activities such as arranging flowers, transplanting, and washing leaves, the total mood disorder score was lowered, indicating a positive effect on the mood of the participants. This study shows that activities such as washing leaves, transplanting, and reading news have a positive effect on the cognitive function of elderly people by increasing brain activity.
\end{abstract}

Aging is associated with a decrease in cognitive function, which includes a decline in brain function and amnesia (Peters, 2006). Long-term cognitive impairment in elderly people can lead to dementia, which is the stage of cognitive function decline (Plassman et al., 2010). Cognitive decline or dementia causes cortical degeneration in the brain,

Received for publication 28 Feb. 2021. Accepted for publication 11 May 2021.

Published online 18 June 2021

This work was supported by the National Research Foundation of Korea (NRF) funded by the Korean government (MSIT) (grant number NRF-2017R1C 1B5076478). This article was supported by the KU Research Professor Program of Konkuk University.

S.-A.P. is the corresponding author. E-mail: sapark42@konkuk.ac.kr.

This is an open access article distributed under the CC BY-NC-ND license (https://creativecommons. org/licenses/by-nc-nd/4.0/). lowers the quality of life of the individual, and increases the burden of care on the family (Gammon, 2014). Therefore, efforts and practices to prevent cognitive decline or dementia in elderly are crucial (Alzheimer's Disease International, 2015).

The Alzheimer's Disease International (2015) reported that lifestyle habits can prevent cognitive decline in elderly. Additionally, it is suggested that a lifestyle that includes leisure activities can improve cognitive ability and delay the onset of dementia (Letenneur et al., 1995; Sanders and Verghese, 2007). However, according to a survey of elderly in South Korea, 99\% spend their leisure time performing passive leisure activities, such as watching television (Jeong et al., 2017). Similarly, nine out of ten elderly individuals in Canada engage in passive leisure activities, such as watching television and reading; the amount of time spent on passive leisure activities increases with age (Arriagada, 2018).
According to an analysis of 460 elderly (aged 60 years or older) living in the United States, most spend a considerable amount of time participating in passive leisure activities, which have a negative effect on their levels of satisfaction in life (Cho et al., 2018).

Gardening is an active leisure activity that has a beneficial impact on the physical, cognitive, and emotional health of elderly (Park et al., 2016). Additionally, it poses a lower risk of injury than other types of physical activity (Pons-Villanueva et al., 2010; Powell et al., 1998). In a previous study, horticultural activities have been regarded as low to moderately intense physical activities for elderly (Park et al., 2011). Interventions that involve horticultural activities have been reported to maintain and improve their physical, psychological, social, and cognitive health (Han et al., 2018; Park et al., 2016, 2017, 2019). For example, horticultural activities could increase the serum tryptophan, kynurenine, and serotonin levels, which are bio-markers for improved cognitive function in elderly people (Park et al., 2020). Kim and Kim (2012) found that elderly individuals with dementia who participated in 18 horticultural activity programs had improved cognitive function in comparison with the control group. Another study reported that the levels of the brain's nerve growth factors, brainderived neurotrophic factor (BDNF) and plateletderived growth factor (PDGF), were significantly improved by performing low- to moderate-intensity horticultural activities (Park et al., 2019).

However, there is insufficient research using electroencephalography (EEG) as a measure for analyzing the cognitive effects of horticultural activities in elderly. Brain activity patterns change according to the degree of cognitive function, and these activity patterns can be measured using EEG (Staufenbiel et al., 2014).

Accordingly, the objective of this study was to compare the physiological and psychological effects in the elderly using EEG readings obtained during horticultural and nonhorticultural leisure activities.

\section{Materials and Methods}

Participants. The inclusion criteria for participation were as follows: a person over 65 years, not having dementia, being ablebodied, being right-handed, having no history of mental illness, and not taking any drugs related to mental disease such as cognitive impairment, depressive disorder, and anxiety disorder (Kim et al., 2020). To recruit participants, a flyer with the study information was distributed among senior community centers in Seoul, South Korea. The individuals who wished to participate in this study were required to complete a consent form and the Korean version of the Mini-Mental State Exam (K-MMSE) (Oh et al., 2010) to exclude individuals who did not fall within the normal range of cognitive ability. As a result, a total of 58 Korean elderly (29 men and 29 women) voluntarily participated in the study. The average K-MMSE score of the participants was $26.81 \pm 1.93$, which is within the normal range (Oh et al., 2010). 


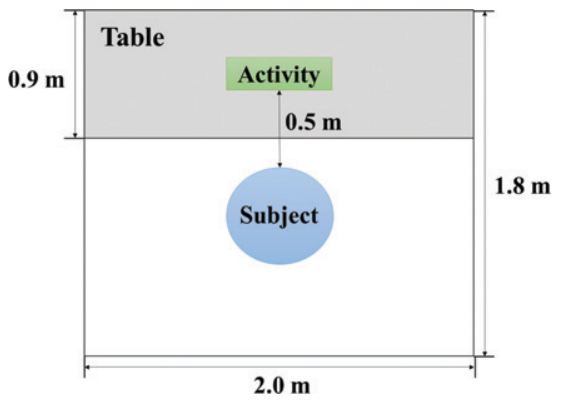

Fig. 1. Room arrangement for the experiment.

The participants were required to fast for $2 \mathrm{~h}$ before starting the experiment because ingredients such as caffeine, which is naturally present in various foods, could stimulate the brain and affect the data (Heckman et al., 2010). The participants also responded to a questionnaire, which comprised a question on their age, gender, use of medicine drugs, etc.; height and weight were measured using an anthropometer (Ok7979; Samhwa, Seoul, South Korea) and a body mass analyser (ioi 353; Jawon Medical, Gyeongsan, South Korea), respectively. Body mass index of participants was also calculated before the experiment.

After completion of the study, the participants received $\$ 15$ as an incentive. This study was approved by the Institutional Review Board of Konkuk University (no. 7001355201809-HR-271).

Experimental conditions. The experiment was conducted in a glasshouse at Konkuk University, Seoul, South Korea. The space for the experiment $(200 \times 160 \mathrm{~cm})$ was created by attaching a white hardboard to the wall directly across from the participant's face. An ivory-colored curtain was placed on both sides of the participant to minimize external stimuli (Fig. 1).

The experimental space was quiet and blocked off from external noise, with the average room temperature set between 23.0 and $26.0^{\circ} \mathrm{C}$, based on the recommended

2 min

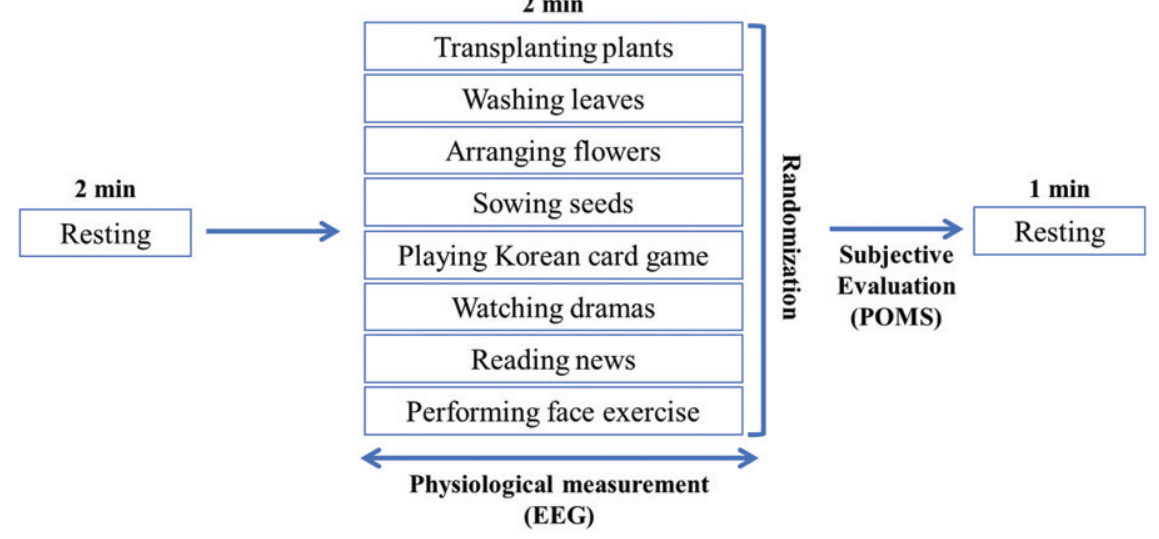

Fig. 2. Study procedure. EEG = electroencephalography; POMS = Profile of Mood State.

temperature by the American Society of Heating, Refrigerating and Air-Conditioning Engineers (2010). The room conditions were regulated as follows: average temperature $24.3 \pm 3.9^{\circ} \mathrm{C}(\mathrm{O}-257$; DRETEC Co., Japan), average relative humidity $23.6 \pm 7.3 \%(\mathrm{O}-$ 257; DRETEC Co.), and average illumination $1996.0 \pm 1024.0$ lx (ST-126; SINCON, South Korea).

Experimental procedure. A cross-over experimental study was conducted. Each participant performed the study procedure as presented in Fig. 2.

Before starting the activity, each participant rested for 2 min by staring at a white wall. Then, the participants performed four horticultural and four nonhorticultural activities for 2 min each (Kim et al., 2020, 2021; Oh et al., 2019) (Table 1, Fig. 3).

The horticultural activities carried out included transplanting plants, washing leaves, arranging flowers in a vase, and sowing seeds, while the nonhorticultural activities included playing Korean card games, watching television, reading the news, and performing face exercises. Each activity was prepared such that it could be performed while sitting; this allowed all participants to comfortably perform the tasks, accounting for the gradual degeneration of the body structure of older people. The results of the National Leisure Activity Research Report of South Korea showed that elderly people mainly enjoy their leisure activities indoors (Ministry of Culture Sports and Tourism, 2019); therefore, only those activities that could be performed while sitting indoors were selected. Before the experiment commenced, the participants received a detailed demonstration of each activity. All participants performed the activities in the same sequence, and all activities that required the use of the hand were performed using the right hand.

The main difference between the two categories of activities is whether natural materials such as plants, soil, and seeds are used. The horticultural activities conducted in this study were designed to allow the elderly to directly see, touch, and smell natural materials for various sensory stimulation.

After finishing each activity, the participants completed a questionnaire to report

Table 1. Description of horticultural and nonhorticultural activities performed by elderly that participated in this study.

Activity
$\begin{gathered}\text { Horticultural } \\ \text { activity }\end{gathered}$

Washing leaves with a cloth

Arranging flowers in a vase

Sowing seeds

Nonhorticultural activity Playing Korean card game

Watching drama

Reading news

Performing face exercises
Description $^{2}$

Transplanting seedlings (Chamaedorea elegans) into a $55-\mathrm{cm} \times 15-\mathrm{cm}$ pot using a hand trowel $(0.1 \mathrm{~kg})$. Participants transplanted an avg of 4 seedlings in 2 mins.

After spraying water using a hand sprayer $(0.2 \mathrm{~kg}$ ) on plants (Epipremnum aureum $)$ in a $55-\mathrm{cm} \times 15-\mathrm{cm}$ pot, the back of the leaves was supported by the left hand and wiped off with a cloth using the right hand.

Holding the stem of the flowers (Gebera, Rosa hybrida, Dendranthema morifolium, and Dianthus caryophyllus) with the left hand and using scissors with the right hand to cut the stem diagonally and putting it in a vase with a ht of $30 \mathrm{~cm}$ and a diam of $20 \mathrm{~cm}$. Participants placed an avg of 11 flower stems in the vase in $2 \mathrm{~min}$.

Digging a hole with a finger in a tray ( 50 holes), sowing three white radish seeds (Raphanus sativus $\mathrm{L}$.) in each hole, and covering them with soil using the right hand. Participants sowed an avg of 18 holes in $2 \mathrm{~min}$.

Using 11 hwatu cards placed on the experimental desk, matching the cards one by one (Korean Go-Stop card game).

Watching a video created by editing the most favored Korean drama program called "Want to Live Together" based on the research by Korea Gallup (2018. 8), in a comfortable position, while the video plays on a laptop.

Reading news articles on life and health on a laptop in a comfortable position.

Following the video of face exercises produced by the Ministry of Health and Welfare to prevent dementia in elderly people.

${ }^{1} 1 \mathrm{~cm}=0.3937$ inch, $1 \mathrm{~kg}=2.2046 \mathrm{lb}$. 
A

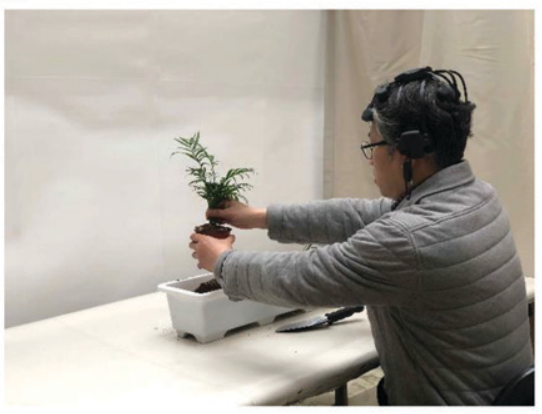

C

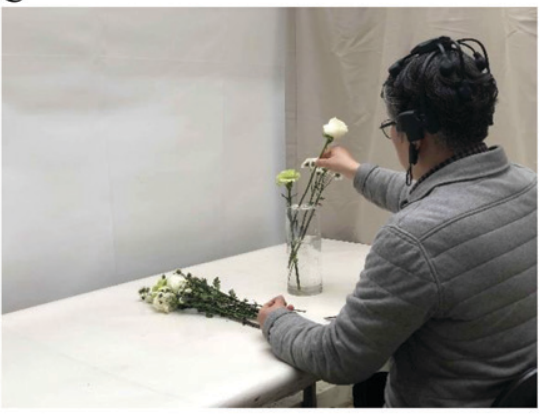

$\mathbf{E}$

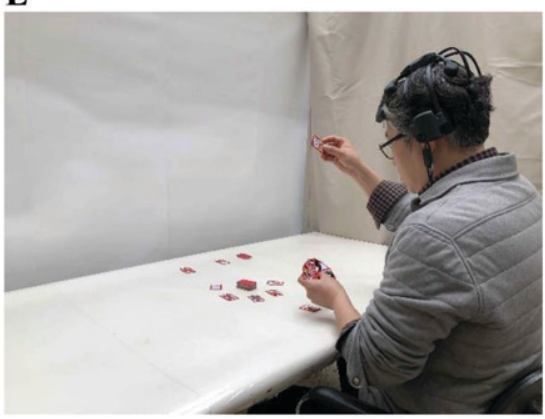

G

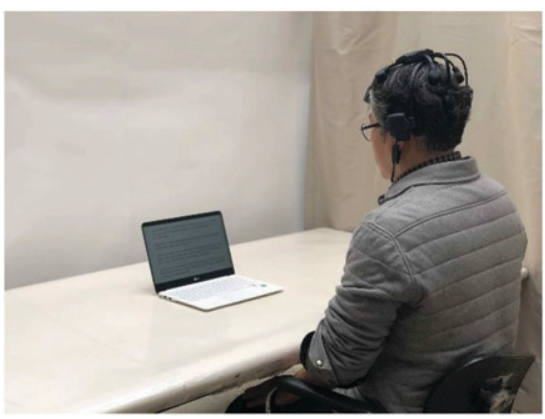

B

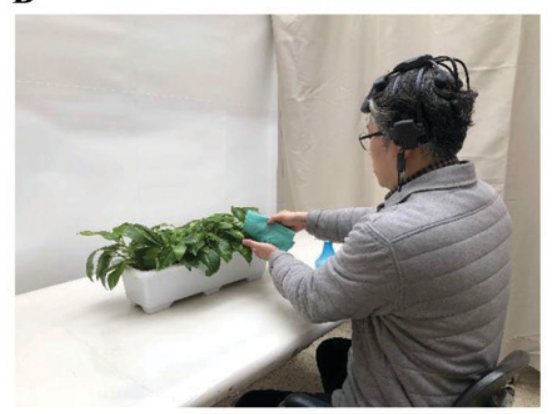

D

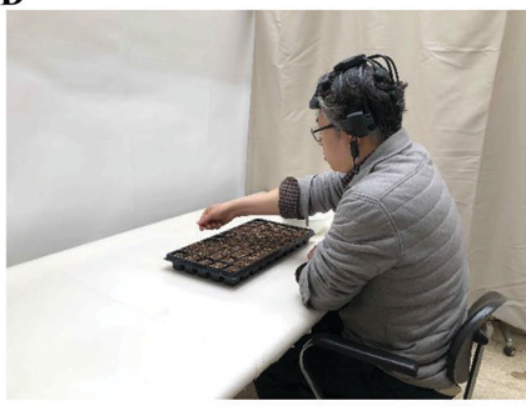

F

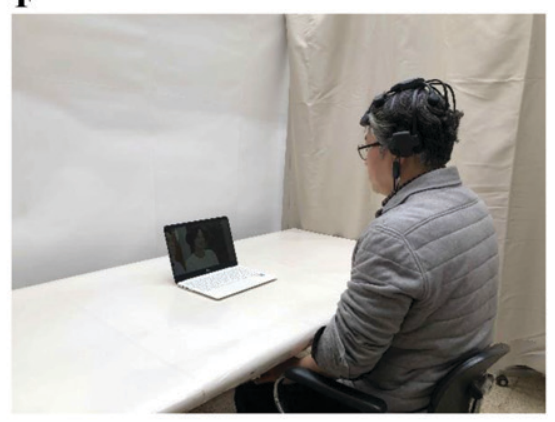

H

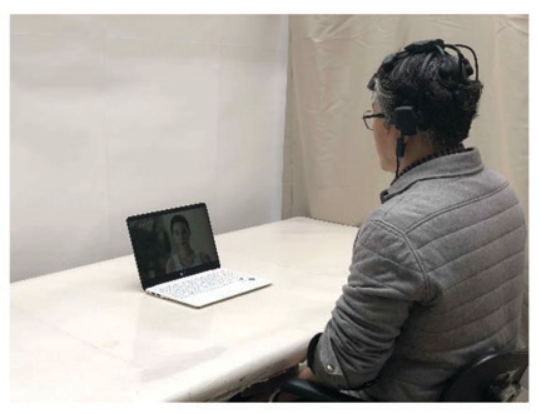

Fig. 3. Experimental performance appearance: (A) transplanting plants, (B) washing leaves with a cloth, (C) arranging flowers, (D) sowing seeds, (E) playing Korean card games, $(\mathbf{F})$ watching dramas, $(\mathbf{G})$ reading news, and $(\mathbf{H})$ performing face exercises.

their subjective emotional state using the Profile of Mood States (POMS); thereafter, they rested for $1 \mathrm{~min}$ and then performed the next activity for $2 \mathrm{~min}$. The male and female participants performed the experiments in random order, separately.

During each experiment, the participants sat in a comfortable position with their chairs placed close to the center of the desk. As the experiment proceeded, the participants were instructed not to move loudly or speak. For each participant, all the activities of the experiment were finished within $\approx$ $60 \mathrm{~min}$.
Measurement. A wireless, dry EEG device (Quick-20; Cognionics, San Diego, CA) was used to measure the cortical electrical activity of each participant during the horticultural and nonhorticultural activities (Fig. 4).

The EEG device used a dry electrode system; and unlike a wet electrode system, it does not need an electrolyte gel, therefore, it minimizes the risk of an electric shock and allows prompt removal of the electrode from the scalp in case of discomfort. The potential difference is determined by placing the dry electrode in contact with the scalp, amplifying the measured electric signals, and collecting the processed data. This device is mainly used in the field of neuroscience (Onton et al., 2016; Stevens et al., 2016), and it has been certified as safe by the European Commission and the Federal Communications Commission.

The EEG monitoring was performed in two regions of the head following the international 10-20 system of electrode placement (Fig. 5); as the prefrontal lobe is involved in cognitive function, the electrodes were placed at the Fp1 (left prefrontal) and Fp2 (right prefrontal) sites (Jasper, 1958; Miller and Cohen, 2001).

The POMS was used to investigate the psychological reaction of elderly people during 


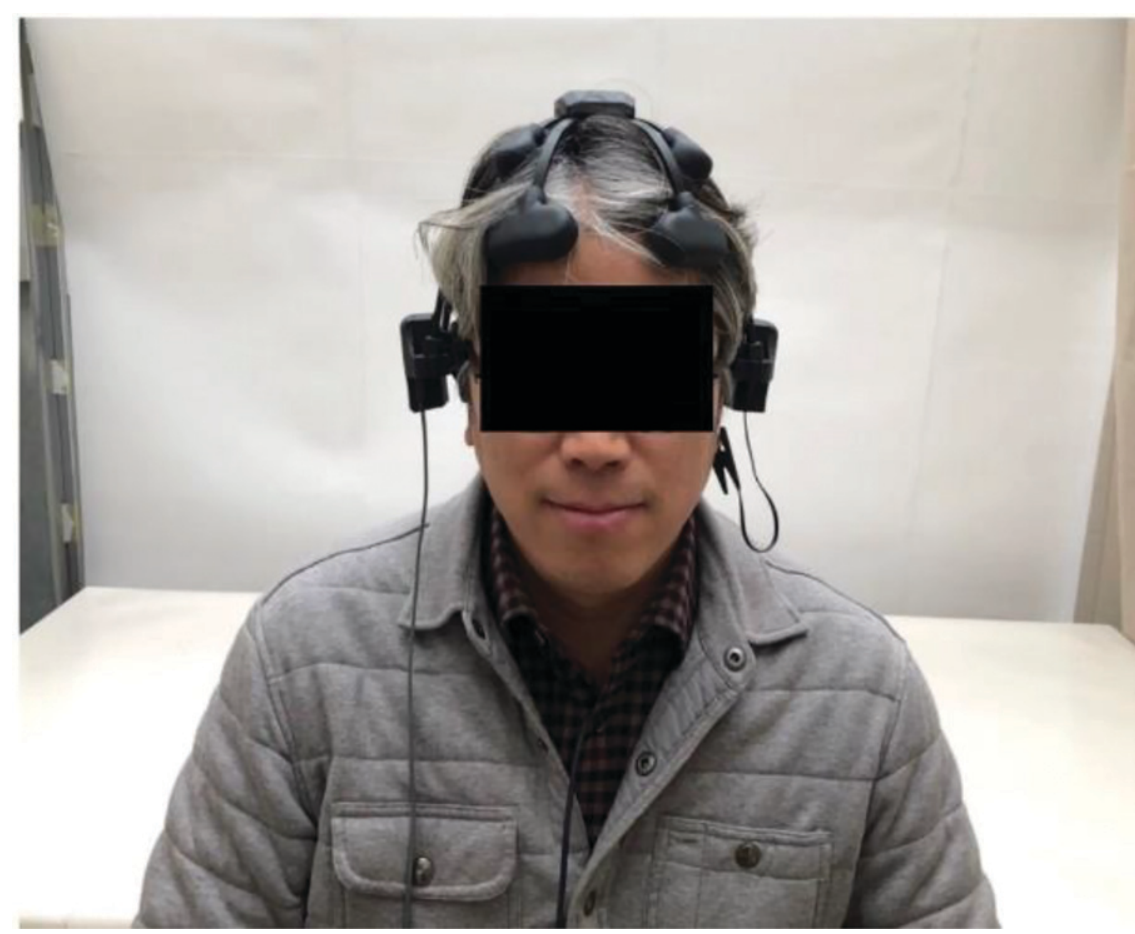

Fig. 4. Dry EEG wireless electroencephalography device (Quick-20; Cognionics, San Diego, CA).

the horticultural and nonhorticultural activities. The POMS is a tool developed by McNair et al. (1971) and has been tested and validated in a variety of contexts. The POMS has been validated and justified for use in elderly people in Korea by Shin (1996). It comprises 30 questions that are divided into "Tension and Anxiety (T-A)," "Depression (D)," "Anger and Hostility (A-H)," "Vigor (V)," "Fatigue (F)," and "Confusion (C)" mood states. The questionnaire enables the analysis of mood by scoring each of the questions on a 5-point scale from "Not at all" (1 point) to "Very much" (5 points). The total mood disturbance (TMD) score is calculated using the following formula: TMD score $=(\mathrm{T}-\mathrm{A})+(\mathrm{D})+(\mathrm{A}-\mathrm{H})+(\mathrm{F})+$ (C) $-(\mathrm{V})$. The lower the TMD score, the more positive the mood (Baker et al., 2002).

Data processing and analysis. EEG data were analyzed using Cognionics Data Acquisition (Cognionics, San Diego, CA) and

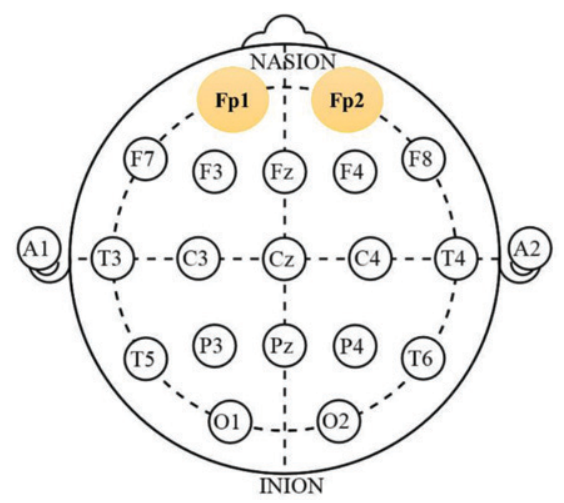

Fig. 5. International 10-20 system of electrode placement (Jasper, 1958). Highlighted sites (Fp1, Fp2) indicate those measured in this study. shoes. descriptive statistics of the mean, standard deviation, and percentage.

\section{Results}

Demographic characteristics. Fifty-eight participants aged $74.02 \pm 4.69$ years participated in the study, with 29 male and 29 female participants (male, $74.69 \pm 4.34$ years; female, $73.34 \pm 5.01$ years) (Table 2). The average body mass index was $26.52 \pm 9.87 \mathrm{~kg} \cdot \mathrm{m}^{-2}$, which was within the range of the criteria for obesity specified by the World Health Organization (WHO Expert Consultation, 2004).

Electroencephalography. During transplanting plants, the RB, RG, and RLB indices were significantly increased $(0.28,0.31$, and 0.06 , respectively) in the left prefrontal lobe of the participants when compared with the other activities $(P<0.001)$ (Table 3$)$. Furthermore, compared with other activities, the $\mathrm{RB}$ and RLB indices in the right prefrontal lobe were significantly increased during washing leaves and reading news $(P<0.01)$. The RLB frequency band is observed in the sensory motor cortex of the brain; it is also called the SMR, and a high value indicates a higher concentration (Bakhtadze et al., 2016). Therefore, the increased RLB index in this study indicates an increase in the attention and concentration of the participants (Bakhtadze et al., 2016).

Additionally, during washing leaves and reading news, the RST index in both prefrontal lobes was significantly higher than that during other activities $(P<0.05)$. The RST index is called the attention quotient and is widely used as an index of brain activation and awakening; a high value indicates increased brain activity (Byun, 2011).

When the results were analyzed according to sex, there were no significant differences in the RB, RG, RLB, or RST among the different types of activities performed by the female participants $(P>0.05)$. In the male participants, the RB and RLB in both prefrontal lobes were significantly higher during washing leaves $(P<0.01)$; and the $\mathrm{RB}, \mathrm{RG}$, and RLB in both prefrontal lobes were significantly higher during reading news than those during other activities $(P<0.01)$.

In previous studies, decreases in beta and gamma bands have been found in those people with dementia and mild cognitive impairment (Missonnier et al., 2010; Stam et al.,

Table 2. Descriptive information of participants who participated in the study.

\begin{tabular}{lcccc}
\hline & Male $(\mathrm{n}=29)$ & Female $(\mathrm{n}=29)$ & Total $(\mathrm{N}=58)$ & \\
\cline { 2 - 4 } Variable & \multicolumn{3}{c}{ Mean $\pm \mathrm{SD}$} & Significance $^{\mathrm{z}}$ \\
\hline Age $($ years $)$ & $74.69 \pm 4.34$ & $73.34 \pm 5.01$ & $74.02 \pm 4.69$ & NS \\
Height $^{\mathrm{y}}(\mathrm{cm})$ & $166.14 \pm 4.66$ & $154.62 \pm 4.41$ & $160.38 \pm 7.35$ & $0.000^{* * *}$ \\
Body weight $^{\mathrm{x}}(\mathrm{kg})$ & $63.97 \pm 10.41$ & $68.71 \pm 25.82$ & $66.34 \pm 19.66$ & NS \\
Body mass index $^{\mathrm{w}}\left(\mathrm{kg} \cdot \mathrm{m}^{-2}\right)$ & $27.21 \pm 13.74$ & $25.82 \pm 2.93$ & $26.52 \pm 9.87$ & NS \\
\hline
\end{tabular}

${ }^{\mathrm{z}}$ Statistical significance as determined using the independent two-sample $t$ test.

${ }^{\mathrm{y}}$ Height was measured using an anthropometer (Ok7979; Samhwa, Seoul, South Korea) without

${ }^{\mathrm{x}}$ Body weight was measured using a body fat analyzer (ioi 353; Jawon Medical, South Korea).

${ }^{\mathrm{w}}$ Body mass index was calculated using the formula [weight $\left.(\mathrm{kg})\right] /\left[\right.$ height $\left.(\mathrm{m})^{2}\right]$.

NS $=$ nonsignificant; $* * *$ Significant at $P<0.001 ; \mathrm{sD}=$ standard deviation. 


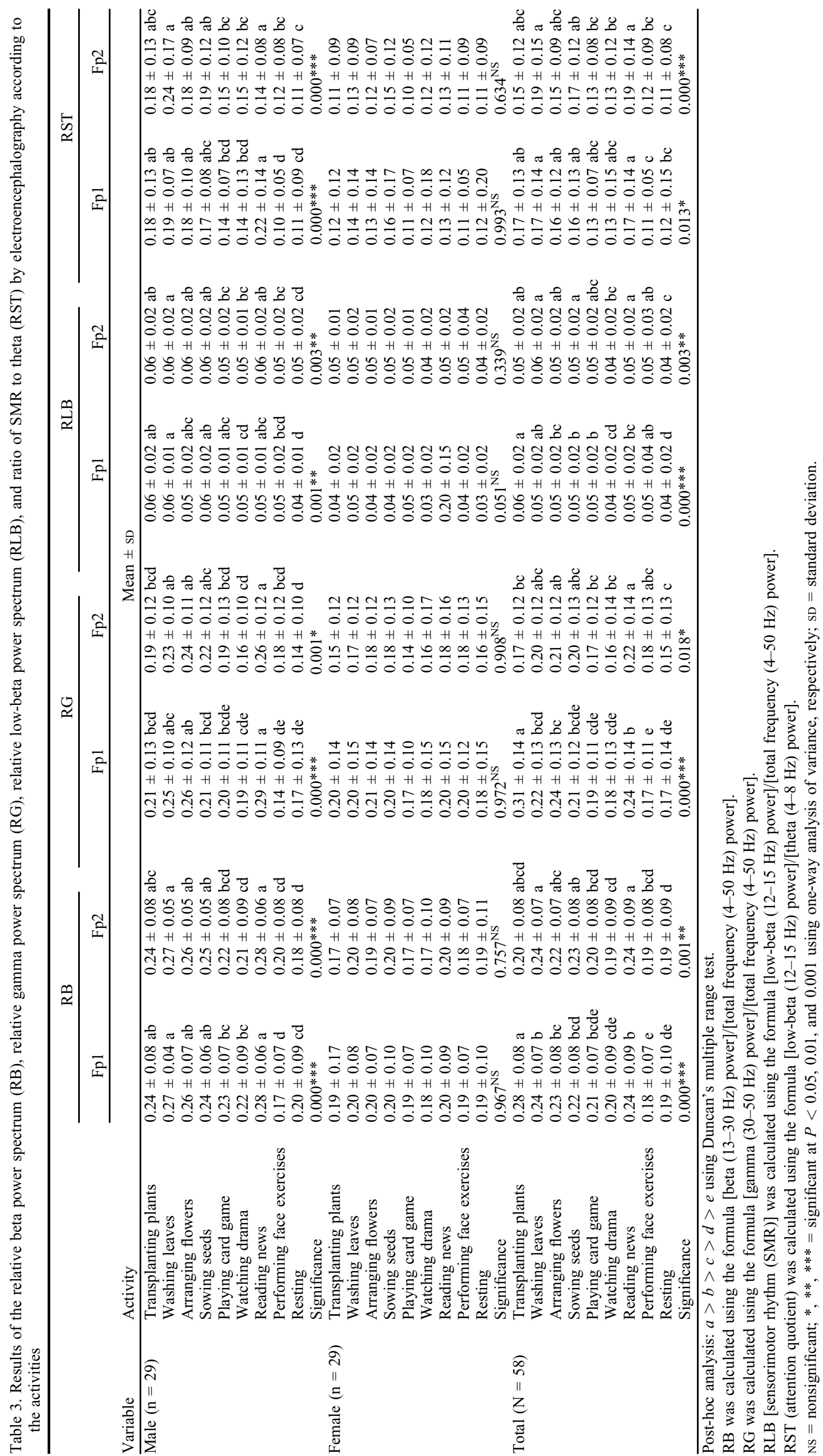


2002). Therefore, training to improve beta and gamma bands has been conducted in neurofeedback research for improving memory and cognitive function in the elderly. Continuous improvement of beta bands improves individual cognitive ability and of gamma bands leads to improvement of recollection in long-term memory and perceptual binding (Egner and Gruzelier, 2001, 2004; Keizer et al., 2010). Accordingly, increased beta and gamma band activities when transplanting plants and washing leaves was considered to reflect cognitive activity in the elderly.

Profile of mood states. The subjective evaluation of the mood states, according to the horticultural and nonhorticultural activities, was performed using the POMS questionnaire. The results of the POMS demonstrated that the TMD scores were the lowest when arranging flowers, transplanting, and washing leaves, indicating that they induced positive mood states $(P<0.001)$ (Fig. 6C). Regarding sex, there were no significant differences in the TMD scores of the different activities in the male participants $(P>0.05)$ (Fig. 6A). The female participants experienced the most positive mood states when arranging flowers $(P<$ 0.001) (Fig. 6B).

\section{Discussion}

This study was conducted using EEG to investigate the effects of indoor horticultural activities compared with those of nonhorticultural activities on the cognitive function of elderly people. The results revealed that the brain activity of elderly people was higher when washing leaves, transplanting plants, and reading news, as evidenced by the increase in RB, RG, and RLB power spectra, and the RST index in the prefrontal lobes (Table 3). In addition, the result of the POMS, which was conducted to evaluate the subjective emotions according to the activities, showed that the participants experienced more positive mood states during horticultural activities than they did during nonhorticultural activities (Fig. 6).

EEG is the recording of the electrical activity of the brain; it can be divided into different EEG frequency bands, such as theta, alpha, beta, and gamma, which reflect different cognitive, sensory, and motor processes (Staufenbiel et al., 2014). The prefrontal cortex, which is the anterior part of the frontal cortex, plays a decisive role in the organization of behavior, language, and cognitive function; therefore, the activation of the prefrontal lobe indicates an improvement in intellect and attention (Carter et al., 2019; Fuster, 2002). In particular, decreased frontal lobe function has been associated with the age-related impairment of episodic memory (Buckner, 2004; Butler et al., 2004; Fjell and Walhovd, 2010).

In this study, during activities such as transplanting plants, washing leaves, and reading news, the RB and RG power spectra were significantly increased in the prefrontal lobes of elderly people (Table 3). In previous studies, a beta power decrease was considered to reflect cortical degenerative changes (Gloor et al., 1977), and an increased beta band activity $(12-20 \mathrm{~Hz})$ has been associated with improvements in memory (Hanslmayr et al., 2012), language processing (Weiss and Mueller, 2012), motor functions (Baker, 2007), and attention (Fan et al., 2007). EEG gamma band activity has also been linked to fluid intelligence and memory functions (Jaušovec and Jaušovec, 2005; Sederberg et al., 2003). Beta and gamma power spectra have both been associated with cognitive and memory functioning in general, and gamma activity has been associated with age-related cognitive decline; therefore, increasing the gamma or beta activity may help improve or maintain cognitive function in elderly people (Staufenbiel et al., 2014). Thus, in this study, the increase in beta and gamma power in the prefrontal lobes during horticultural and news-reading activities implies the possibility of improvement in the cognitive function of elderly people.

The RLB and RST indices obtained during activities such as transplanting plants, washing leaves, sowing seeds, and reading news were significantly increased in the prefrontal lobes compared with those obtained during other activities (Table 3). The RLB index refers to a frequency band in the lower area of the beta power spectrum that is related to cognitive functions, such as reaction time, complex psychomotor skills (Doppelmayr and Weber, 2011; Ros et al., 2009), improved memory (Barnea et al., 2005; Hoedlmoser et al., 2008; Vernon et al., 2003), and spatial ability (Doppelmayr and Weber, 2011). The theta waves in the 4-7 Hz range occur in a shallow-sleep state or during rapid-eye-movement sleep (Han and Hong, 2017). In a previous study, it was reported that the relative theta waves of elderly people gradually increase with age (Remond, 1978), an increase in the degree of cognitive impairment, and a decrease in the hippocampal volume (Grunwald et al., 2001; Prichep et al., 1994). Thus, the RST index, which was calculated as the ratio of low-beta power to theta power, can also be regarded as an indicator of cognitive function in elderly people, while an increase in the RLB and RST indices during horticultural and news-reading activities indicates increased cognitive activity in the prefrontal lobes.

A previous study reported that the levels of the brain nerve growth factors BDNF and PDGF in elderly people were significantly increased when performing $20 \mathrm{~min}$ of low- to moderate-intensity gardening activities (Park et al., 2019). In addition, a study aimed at developing and conducting a total of 14 horticultural therapy programs focused on indoor horticultural activities for the cognitive rehabilitation of patients with dementia reported a cognitive therapeutic effect that improved the rate of sugar metabolism in the temporal-parietal lobe of patients with Alzheimer-type dementia (Cho, 2008). Therefore, the EEG results in this study are believed to be due to the generation and loss of nerve cells in the hippocampus, and changes in the metabolic processes in the cortex as a result of the horticultural activities may also have influenced changes in brain waves (Rae-Grant et al., 1987; Vinogradova, 1995).

The results of this study showed that there were gender differences in the EEG responses of the elderly according to the nonhorticultural activities and horticultural activities. In previous studies, when performing cognitive tasks such as divergent thinking (Razumnikova, 2004), intensive assignment (Kim et al., 2020), and spatial and analytic tasks (Corsi-Cabrera et al., 1993), changes in EEG between genders were also reported differently. This can be explained by the structural and functional differences of the brain between genders such as cerebral blood flow (Gur et al., 1982), psychoneuroendocrine response to stress and to challenging situations (Frankenhaeuser et al., 1978), and morphological, neurochemical, and neurophysiological data of the sex dimorphism in hemispheric interactions (Kimura, 1987; Shaywitz et al., 1995; Volf and Razumnikova, 1999; Zaidel et al., 1995). Although the origin, anatomical, or functional conclusions of the observed gender differences cannot be drawn due to the nature of this experiment, the findings of this study are supported by previous findings that males had a higher contribution of relative beta power to total power than females in a variety of situations, such as at rest (CorsiCabrera et al., 1989), cognitive tasks (CorsiCabrera et al., 1993), and information processing (Beaumont et al., 1978).

In conclusion, we revealed that horticultural activities such as washing leaves, sowing seeds, and transplanting plants, when performed as leisure activities, have a positive effect on cognitive function by increasing brain activity in elderly people. The results of this study demonstrated significantly higher brain activity levels in the elderly during these activities than those during the general leisure activities, such as watching TV programs, playing card games, and doing facial exercises. In addition, horticultural activities had a positive effect on the emotional stability of elderly people in this study.

Increased changes in brain activity such as increasing gamma or beta activity may lead to improving or maintaining cognitive and memory functioning (Staufenbiel et al., 2014). Therefore, for the elderly, performing a regular horticultural activity for leisure could activate their brain waves, which could lead to the recovery and improvement of cognitive and emotional function.

Further studies are needed to explore the effects of extended performance of various horticultural activities in patients with dementia or in those who are cognitively disabled to assess their cognitive health. Moreover, a follow-up study to determine the cognitive correlation between neural factors in the hippocampus and brain waves through horticultural intervention would be interesting. In addition, studies are warranted on the causes of the differences in the brain waves and subjective mental state between genders when performing horticultural activities. 
2

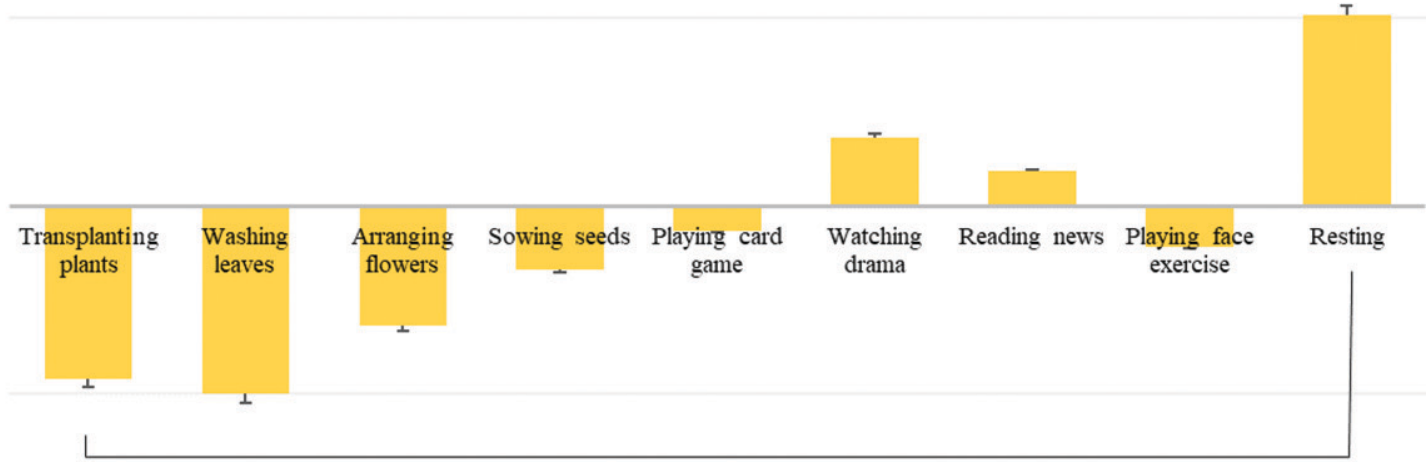

NS

$-4$

$-6$

$-8$

B

FEMALE

2

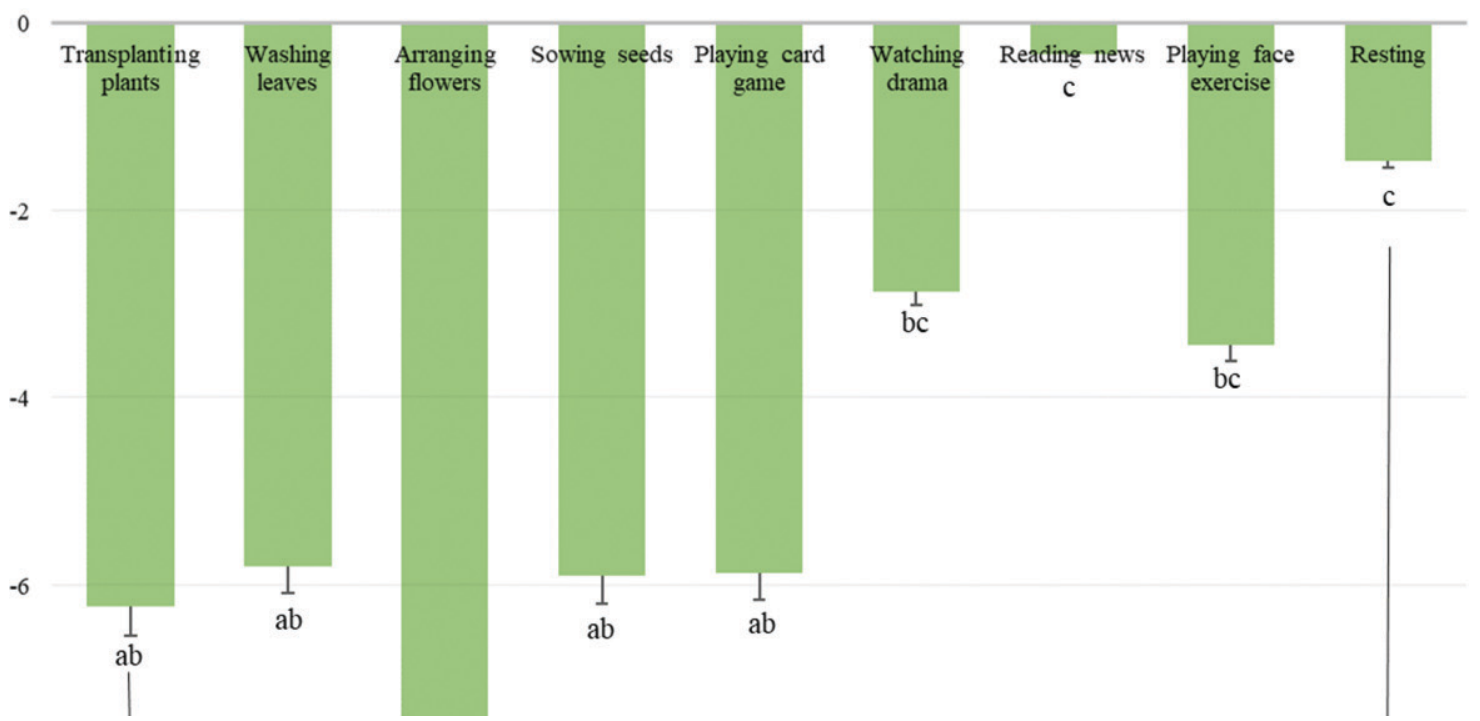

Fig. 6. Comparisons of the total mood disturbance (TMD) score in the Profile of Mood States (POMS) questionnaire between activities performed by (A) male $(\mathrm{n}=29)$, $(\mathbf{B})$ female $(\mathrm{n}=29)$, and $(\mathbf{C})$ all participants $(\mathrm{N}=58) .{ }^{* * *} P<0.001$; $\mathrm{NS}=$ nonsignificant as determined by one-way analysis of variance. Post-hoc analysis: $a>b>c$ by Duncan's multiple range test. 


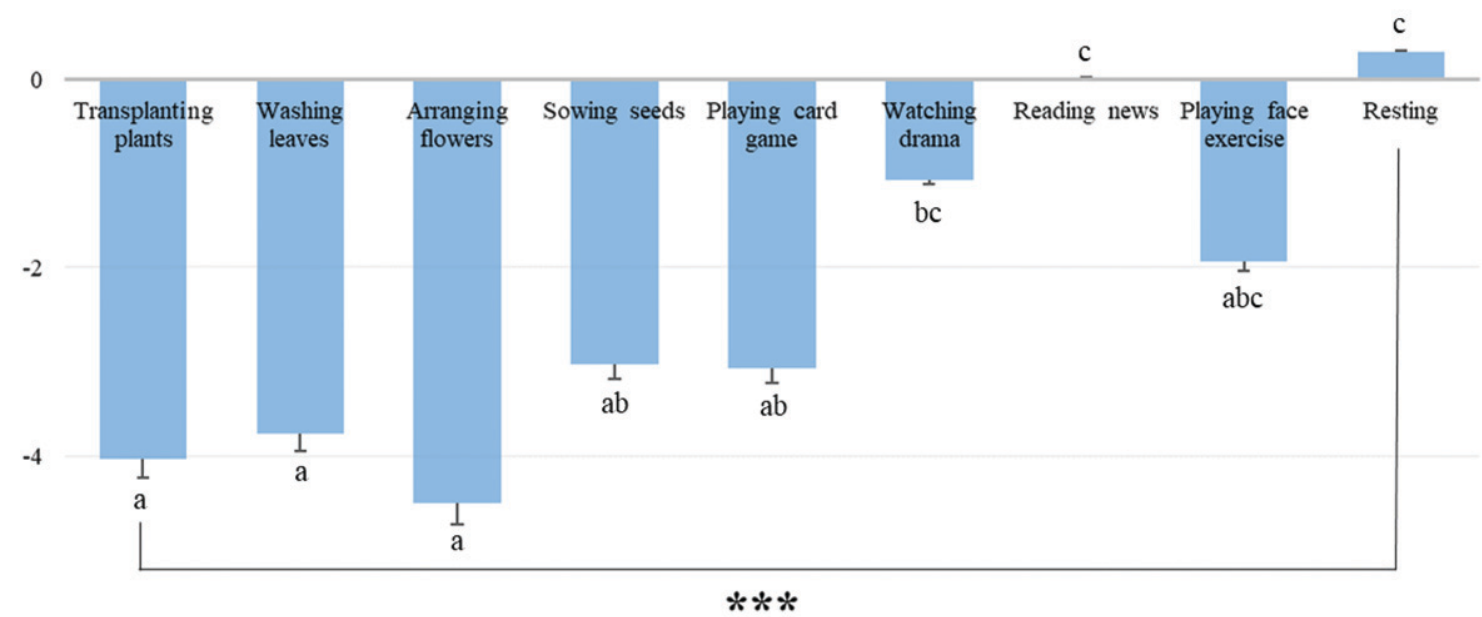

$-6$

$-8$

Fig. 6. (Continued.)

\section{Literature Cited}

Alzheimer's Disease International. 2015. World Alzheimer report 2015: The global impact of dementia: An analysis of prevalence, incidence, cost and trends. Alz. Dis. Int., London.

American Society of Heating, Refrigerating, AirConditioning Engineers. 2010. Thermal environmental conditions for human occupancy. ASHRAE, Atlanta.

Arriagada, P. 2018. Insights on Canadian society a day in the life: How do older Canadians spend their time? Statistics Canada. 10 July 2020. $<$ https://www150.statcan.gc.ca/n1/en/pub/75006-x/2018001/article/54947-eng.pdf?st=Cum $\mathrm{cI} 9 \mathrm{nV}>$.

Baker, F., M. Denniston, J. Zabora, A. Polland, and W.N. Dudley. 2002. A POMS short form for cancer patients: Psychometric and structural evaluation. Psycho-oncol. 11:273-281, doi: https://doi.org/10.1002/pon.564.

Baker, S.N. 2007. Oscillatory interactions between sensorimotor cortex and the periphery. Curr. Opin. Neurobiol. 17:649-655, doi: https://doi. org/10.1016/j.conb.2008.01.007.

Bakhtadze, S., M. Beridze, N. Geladze, N. Khachapuridze, and N. Bornstein. 2016. Effect of EEG biofeedback on cognitive flexibility in children with attention deficit hyperactivity disorder with and without epilepsy. Appl. Psychophysiol. Biofeedback 41:71-79, doi: https://doi. org/10.1007/s10484-015-9314-9.

Barnea, A., A. Rassis, and E. Zaidel. 2005. Effect of neurofeedback on hemispheric word recognition. Brain Cogn. 59:314-321, doi: https:// doi.org/10.1016/j.bandc.2004.05.008.

Beaumont, J.G., A.R. Mayes, and M.D. Rugg. 1978. Asymmetry in EEG alpha coherence and power: Effects of task and sex. Electroencephalogr. Clin.
Neurophysiol. 45:393-401, doi: https://doi.org/ 10.1016/0013-4694(78)90190-6.

Buckner, R.L. 2004. Memory and executive function in aging and $\mathrm{AD}$ : Multiple factors that cause decline and reserve factors that compensate. Neuron 44:195-208, doi: https://doi.org/ 10.1016/j.neuron.2004.09.006.

Butler, K.M., M.A. McDaniel, C.C. Dornburg, A.L. Price, and H.L. Roediger. 2004. Age differences in veridical and false recall are not inevitable: The role of frontal lobe function. Psychon. Bull. Rev. 11:921-925, doi: https://doi.org/10.3758/ BF03196722.

Byun, Y.E. 2011. The effect of neurofeedback training on age differences groups in adolescence. J. Korea Acad. Coop. Soc. 12:2561-2566, doi: https://doi.org/10.5762/kais.2011.12.6.2561.

Carter, R., S. Aldridge, M. Page, and S. Parker. 2019. The human brain book: An illustrated guide to its structure, function, and disorders. Penguin, London.

Cho, D., J. Post, and S.K. Kim. 2018. Comparison of passive and active leisure activities and life satisfaction with aging. Geriatr. Gerontol. Intl. 18: 380-386, doi: https://doi.org/10.1111/ggi.13188.

Cho, M.K. 2008. Horticultural therapy as nonpharmacological treatment for the improvement of cognitive function and BPSD in dementia. Konkuk Univ., Seoul, PhD Diss.

Corsi-Cabrera, M., J. Ramos, M.A. Guevara, C. Arce, and S. Gutierrez. 1993. Gender differences in the EEG during cognitive activity. Intl. J. Neurosci. 72:257-264, doi: https://doi. org/10.3109/00207459309024114.

Corsi-Cabrera, M., P. Herrera, and M. Malvido. 1989. Correlation between EEG and cognitive abilities: Sex differences. Intl. J. Neurosci. 45: 133-141, doi: https://doi.org/10.3109/0020745 8908986226.
Doppelmayr, M. and E. Weber. 2011. Effects of SMR and theta/beta neurofeedback on reaction times, spatial abilities, and creativity. J. Neurother. 15:115-129, doi: https://doi.org/10.1080/ 10874208.2011.570689.

Egner, T. and J.H. Gruzelier. 2001. Learned self-regulation of EEG frequency components affects attention and event-related brain potentials in humans. Neuroreport 12:4155-4159, doi: https:// doi.org/10.1097/00001756-200112210-00058.

Egner, T. and J.H. Gruzelier. 2004. EEG biofeedback of low beta band components: Frequencyspecific effects on variables of attention and event-related brain potentials. Clin. Neurophysiol. 115:131-139, doi: https://doi.org/10.1016/ S1388-2457(03)00353-5.

Fan, J., J. Byrne, M.S. Worden, K.G. Guise, B.D. McCandliss, J. Fossella, and M.I. Posner. 2007. The relation of brain oscillations to attentional networks. J. Neurosci. 23:6197-6206, doi: https:// doi.org/10.1523/JNEUROSCI.1833-07.2007.

Fjell, A.M. and K.B. Walhovd. 2010. Structural brain changes in aging: Courses, causes and cognitive consequences. Rev. Neurosci. 21:187221, doi: https://doi.org/10.1515/REVNEURO. 2010.21.3.187.

Frankenhaeuser, M., M.R. Von Wright, A. Collins, J. Von Wright, G. Sedvall, and C.G. Swahn. 1978. Sex differences in psychoneuroendocrine reactions to examination stress. Psychosom. Med. 40:334-343, doi: https://doi.org/10.1097/ 00006842-197806000-00006.

Fuster, J.M. 2002. Frontal lobe and cognitive development. J. Neurocytol. 31:373-385, doi: https://doi.org/10.1023/A:1024190429920.

Gammon, K. 2014. Neurodegenerative disease: Brain windfall. Nature 515:299-300, doi: https:// doi.org/10.1038/nj7526-299a. 
Gloor, P., G. Ball, and N. Schaul. 1977. Brain lesions that produce delta waves in the EEG. Neurology 27:326, doi: https://doi.org/10.1212/ wnl.27.4.326.

Grunwald, M., F. Busse, A. Hensel, F. Kruggel, S. Riedel-Heller, H. Wolf, T. Arendt, and H.J. Gertz. 2001. Correlation between cortical $\theta$ activity and hippocampal volumes in health, mild cognitive impairment, and mild dementia. J. Clin. Neurophysiol. 18:178-184, doi: https:// doi.org/10.1097/00004691-200103000-00010.

Gur, R.C., R.E. Gur, W.D. Obrist, J.P. Hungerbuhler, D. Younkin, A.D. Rosen, B.E. Skolnick, and M. Reivich. 1982. Sex and handedness differences in cerebral blood flow during rest and cognitive activity. Sci. 217:659-661, doi: https://doi.org/10.1126/science.7089587.

Han, A.R., S.A. Park, and B.E. Ahn. 2018. Reduced stress and improved physical functional ability in elderly with mental health problems following a horticultural therapy program. Complement. Ther. Med. 38:19-23, doi: https://doi.org/10.1016/j.ctim.2018.03.011.

Han, Y.J. and C.H. Hong. 2017. The effects of neurofeedback on the attention in college students with ADHD. J. Korea Acad. Coop. Soc. 18: 245-255, doi: https://doi.org/10.5762/kais.2017. 18.1.245.

Hanslmayr, S., T. Staudigl, and M.C. Fellner. 2012. Oscillatory power decreases and longterm memory: The information via desynchronization hypothesis. Front. Hum. Neurosci. 6: 74, doi: https://doi.org/org/10.3389/fnhum. 2012.00074 .

Heckman, M.A., J. Weil, and E.G. de Mejia. 2010. Caffeine (1, 3, 7-trimethylxanthine) in foods: A comprehensive review on consumption, functionality, safety, and regulatory matters. J. Food Sci. 75:R77-R87, doi: https://doi.org/ 10.1111/j.1750-3841.2010.01561.x.

Hoedlmoser, K., T. Pecherstorfer, G. Gruber, P. Anderer, M. Doppelmayr, W. Klimesch, and M. Schabus. 2008. Instrumental conditioning of human sensorimotor rhythm $(12-15 \mathrm{~Hz})$ and its impact on sleep as well as declarative learning. Sleep 31:1401-1408, doi: https://doi.org/ 10.5665/sleep/31.10.1401.

Jasper, H.H. 1958. The ten twenty electrode system of the international federation. Electroencephalogr. Clin. Neurophysiol. 10:370-375.

Jaušovec, N. and K. Jaušovec. 2005. Differences in induced gamma and upper alpha oscillations in the human brain related to verbal/performance and emotional intelligence. Intl. J. Psychophysiol. 56:223-235, doi: https://doi.org/ 10.1016/j.ijpsycho.2004.12.005.

Jeong, K.H., Y.H. Oh, E.N. Kang, K.R. Kim, Y.K. Lee, M.A. Oh, N.H. Hwang, S.J. Kim, S.H. Lee, S.G. Lee, and S.E. Hong. 2017. Survey on the elderly 2017. Minis. Health Welfare and Kor. Inst. Health Soc. Affairs, Sejong.

Keizer, A.W., R.S. Verment, and B. Hommel. 2010. Enhancing cognitive control through neurofeedback: A role of gamma-band activity in managing episodic retrieval. Neuroimage 49:3404-3413, doi: https://doi.org/10.1016/j. neuroimage.2009.11.023.

Kim, S.O., Y.A. Oh, and S.A. Park. 2020. Foliage plants improve concentration and emotional condition of elementary school students performing an intensive assignment. HortScience 55:378-385, doi: https://doi.org/10.21273/ HORTSCI14757-19.

Kim, M.H. and J.M. Kim. 2012. The effect of an occupational therapeutic intervention program using horticultural therapy on cognition and daily living performance of the elderly with dementia. J. Korean Soc. Community Occup. Ther. 2:75-84

Kim, S.O., J.E. Jeong, Y.A. Oh, H.R. Kim, and S.A. Park. 2021. Comparing concentration levels and emotional states of children using electroencephalography during horticultural and nonhorticultural activities. HortScience 56:324-329, doi: https://doi.org/10.21273/HORTSCI15522-20.

Kimura, D. 1987. Are men's and women's brains really different? Can. Psychol. 28:133-147, doi: https://doi.org/10.1037/h0079885.

Letenneur, L., J.F. Dartigue, M. Zarrouk, D. Commenges, and P. Barberger-Gateau. 1995. Social and leisure activities and risk of dementia: A prospective longitudinal study. J. Amer. Geriatr. Soc. 43:485-490, doi: https://doi.org/ 10.1111/j.1532-5415.1995.tb06093.x.

McNair, D.M., M. Lorr, and L.F. Droppleman. 1971 Manual for profile of mood states. Educational and Industrial Testing Services, San Diego, CA. 10 Dec. 2020. < https://www.statisticssolutions. com/profile-of-mood-states-poms/ $>$.

Miller, E.K. and J.D. Cohen. 2001. An integrative theory of prefrontal cortex function. Annu. Rev. Neurosci. 24:167-202, doi: https://doi.org/ 10.1146/annurev.neuro.24.1.167.

Ministry of Culture Sports and Tourism. 2019. National leisure activity research report 2019. Minis. Cult. Sports Tourism, Sejong, South Korea.

Missonnier, P., F.R. Herrmann, A. Michon, L. Fazio-Costa, G. Gold, and P. Giannakopoulos. 2010. Early disturbances of gamma band dynamics in mild cognitive impairment. J. Neural Transm. (Vienna) 117:489-498, doi: https://doi.org/10.1007/s00702-010-0384-9.

Oh, E., Y. Kang, J.H. Shin, and B.K. Yeon. 2010. A validity study of K-MMSE as a screening test for dementia: Comparison against a comprehensive neuropsychological evaluation. Dement. Neurocognitive Disord. 9:8-12.

Oh, Y.A., S.O. Kim, and S.A. Park. 2019. Real foliage plants as visual stimuli to improve concentration and attention in elementary students. Intl. J. Environ. Res. Public Health 16:796, doi: https://doi.org/10.3390/ijerph16050796.

Onton, J.A., D.Y. Kang, and T.P. Coleman. 2016. Visualization of whole-night sleep EEG from 2-channel mobile recording device reveals distinct deep sleep stages with differential electrodermal activity. Front. Hum. Neurosci. 10:605, doi: https://doi.org/10.3389/fnhum.2016.00605.

Park, S.A., A.Y. Lee, H.G. Park, and W.L. Lee. 2019. Benefits of gardening activities for cognitive function according to measurement of brain nerve growth factor levels. Intl. J. Environ. Res. Public Health 16:760, doi: https://doi. org/10.3390/ijerph16050760.

Park, S.A., A.Y. Lee, H.G. Park, K.C. Son, D.S Kim, and W.L. Lee. 2017. Gardening intervention as a low- to moderate-intensity physical activity for improving blood lipid profiles, blood pressure, inflammation, and oxidative stress in women over the age of 70: A pilot study. HortScience 52:200-205, doi: https:// doi.org/10.21273/HORTSCI11232-16.

Park, S.A., S.Y. Son, A.Y. Lee, H.G. Park, W.L. Lee, and C.H. Lee. 2020. Metabolite profiling revealed that a gardening activity program improves cognitive ability correlated with BDNF levels and serotonin metabolism in the elderly. Intl. J. Environ. Res. Public Health 17:541, doi: https://doi.org/10.3390/ijerph17020541.

Park, S.A., A.Y. Lee, G.L. Lee, D.S. Kim, W.S. Kim, C.A. Shoemaker, and K.C. Son. 2016. Horticultural activity interventions and outcomes: A review. Hort. Sci. Technol. 34:513-527, doi: https://doi.org/10.12972/kjhst.20160053.
Park, S.A., K.S. Lee, and K.C. Son. 2011. Determining exercise intensities of gardening tasks as a physical activity using metabolic equivalents in older adults. HortScience 46:1706-1710, doi: https://doi.org/10.21273/hortsci.46.12.1706.

Peters, R. 2006. Ageing and the brain. Postgrad. Med. J. 82:84-88, doi: https://doi.org/10.1136/ pgmj.2005.036665.

Plassman, B.L., J.W. Williams, J.R. Burke, T. Holsinger, and S. Benjamin. 2010. Systematic review: Factors associated with risk for and possible prevention of cognitive decline in later life. Ann. Intern. Med. 153:182-193, doi: https://doi. org/10.7326/0003-4819-153-3-201008030-00258.

Pons-Villanueva, J., M. Seguí-Gómez, and M.A. Martínez-González. 2010. Risk of injury according to participation in specific physical activities: A 6-year follow-up of 14356 participants of the SUN cohort. Intl. J. Epidemiol. 39:580-587, doi: https://doi.org/10.1093/ije/dyp319.

Powell, K.E., G.W. Heath, M.J. Kresnow, J.J. Sacks, and C.M. Branche. 1998. Injury rates from walking, gardening, weightlifting, outdoor bicycling, and aerobics. Med. Sci. Sports Exerc. 30:1246-1249, doi: https://doi.org/ 10.1097/00005768-199808000-00010.

Prichep, L.S., E.R. John, S.H. Ferris, B. Reisberg, M. Almas, K. Alper, and R. Cancro. 1994. Quantitative EEG correlates of cognitive deterioration in the elderly. Neurobiol. Aging 15: 85-90, doi: https://doi.org/10.1016/0197-4580 (94)90147-3.

Rae-Grant, A., W. Blume, C. Lau, V.C. Hachinski, M. Fisman, and H. Merskey. 1987. The electroencephalogram in Alzheimer-type dementia: A sequential study correlating the electroencephalogram with psychometric and quantitative pathologic data. Arch. Neurol. 44:50-54, doi: https:// doi.org/10.1001/archneur.1987.00520130042015.

Razumnikova, O.M. 2004. Gender differences in hemispheric organization during divergent thinking: An EEG investigation in human subjects. Neurosci. Lett. 362:193-195, doi: https:// doi.org/10.1016/j.neulet.2004.02.066.

Remond, A. 1978. Handbook of electroencephalography and clinical neurophysiology. Neurosci. 4:691, doi: https://doi.org/10.1016/0306-4522 (79)90146-5.

Ros, T., M.J. Moseley, P.A. Bloom, L. Benjamin, L.A. Parkinson, and J.H. Gruzelier. 2009. Optimizing microsurgical skills with EEG neurofeedback. BMC Neurosci. 10:1-10, doi: https:// doi.org/10.1186/1471-2202-10-87.

Sanders, A. and J. Verghese. 2007. Leisure activities and the risk of dementia in the elderly. Res. Pract. Alzheimers Dis. 12:54-58.

Sederberg, P.B., M.J. Kahana, M.W. Howard, E.J. Donner, and J.R. Madsen. 2003. Theta and gamma oscillations during encoding predict subsequent recall. J. Neurosci. 23:10809-10814, doi: https:// doi.org/10.1523/jneurosci.23-34-10809.2003.

Shaywitz, B.A., S.E. Shaywltz, K.R. Pugh, R.T. Constable, P. Skudlarski, R.K. Fulbright, R.A. Bronen, J.M. Flecher, D.P. Shankweiler, L. Katz, and J.C. Gore. 1995. Sex differences in the functional organization of the brain for language. Nature 373:607-609, doi: https://doi. org/10.1038/373607a0.

Shin, Y.H. 1996. A study on verification of the Profile of Mood States (POMS) for Korean elders. J. Korean Acad. Nurs. 26:743-758.

Sowndhararajan, K., H. Cho, B. Yu, and S. Kim. 2015. Effect of olfactory stimulation of isomeric aroma compounds, (+)-limonene and terpinolene on human electroencephalographic activity. Eur. J. Integr. Med. 7:561-566, doi: https://doi.org/10.1016/j.eujim.2015.08.006. 
Stam, C.J., A.M.V.C. van Walsum, Y.A. Pijnenburg, H.W. Berendse, J.C. de Munck, P. Scheltens, and B.W. van Dijk. 2002. Generalized synchronization of MEG recordings in Alzheimer's disease: Evidence for involvement of the gamma band. J. Clin. Neurophysiol. 19:562-574, doi: https://doi. org/10.1097/00004691-200212000-00010.

Staufenbiel, S.M., A.M. Brouwer, A.W. Keizer, and N.C. van Wouwe. 2014. Effect of beta and gamma neurofeedback on memory and intelligence in the elderly. Biol. Psychol. 95:74-85, doi: https://doi.org/10.1016/j.biopsycho.2013.05.020.

Stevens, R., T. Galloway, D. Halpin, and A. Willemsen-Dunlap. 2016. Healthcare teams neurodynamically reorganize when resolving uncertainty. Entropy 18:427, doi: https://doi. org/10.3390/e18120427.

Vernon, D., T. Egner, N. Cooper, T. Compton, C. Neilands, A. Sheri, and J. Gruzelier. 2003. The effect of training distinct neurofeedback protocols on aspects of cognitive performance. Intl. J. Psychophysiol. 47:78-85, doi: https://doi.org/ 10.1016/S0167-8760(02)00091-0.

Vinogradova, O.S. 1995. Expression, control, and probable functional significance of the neuronal theta-rhythm. Prog. Neurobiol. 45:523-583, doi: https://doi.org/10.1016/0301-0082(94)00051-I.

Volf, N.V. and O.M. Razumnikova. 1999. Sex differences in EEG coherence during a verbal memory task in normal adults. Intl. J. Psychophysiol.
34:113-122, doi: https://doi.org/10.1016/S01678760(99)00067-7.

Weiss, S. and H.M. Mueller. 2012. Too many betas do not spoil the broth: The role of beta brain oscillations in language processing. Front. Psychol. 3:201, doi: https://doi.org/10.3389/fpsyg.2012.00201.

WHO Expert Consultation, 2004. Appropriate body-mass index for Asian populations and its implications for policy and intervention strategies. Lancet 363:157-163, doi: https://doi.org/ 10.1016/S0140-6736(03)15268-3.

Zaidel, E., F. Aboitiz, and J. Clarke. 1995. Sexual dimorphism in interhemispheric relations: Anatomical-behavioral convergence. Biol. Res. 28: 27-43. 